\title{
Correlation of Dental Caries, Total Proteins, Total Antioxidant Capacity, Immunoglobulin A and $G$ in Children At The Age from 4-6 Years
}

\author{
Naskova S. ${ }^{1}$, Iljovska S. ${ }^{2}$ Krstevska M. ${ }^{3}$ J.PavlevskaM. ${ }^{2}$,Jankulovska \\ M. ${ }^{2,}$ Veninov T., ${ }^{2,}$ Alimani -Jakupi J. ${ }^{4}$ \\ l, Goce Delcev" University in Stip, Faculty of Medical Sciences, Department of Dental Medicine-Stip, \\ Macedonia. \\ 2 ,Ss. Cyril and Methodius” UniversityinSkopje,FacultyofDentistry-Skopje, Macedonia. \\ ${ }^{3}$, ,Ss. Cyril and Methodius” University in Skopje, Faculty of Medikal-Skopje, Macedonia. \\ ${ }^{4}$ Privatepractice-Preventivadental,Gostivar,Macedonia
}

\begin{abstract}
This study is aimed to : assess the level of total proteins in the saliva; to assess the level of the immunoglobulin's IgA and IgG in the saliva; to assess the antioxidant capacity of the saliva; to analyze the correlation of the dental status and the level of activity of the dental caries in every examined parameter separately.

Materials and methods: For the realization of our goals weincluded 74 preschool children (35 female and 39 male), picked randomly, at the age from 4-6 years, from the elementary schools in Shtip which were divided into two groups: experimental and control.

Every examinee was clinically examined (dmft and intensity of dental caries) and laboratory investigations were carries out (total protein levels, antioxidant capacity, IgA and IgG in the saliva).

Results: The results from our study that referred to the total amount of proteins in the saliva of children with primary teeth, from the control group, were significantly greater in correlation to the value of the same in children from the experimental group ( $p<0,01)$; we established a negative medium strong significant correlation $(p<0,05)$ between the values of the total protein in the saliva of children with primary teeth and the presence of dental caries; the values of the total antioxidant capacity of the saliva in children with a primary dentition from the control group are significantly greater in correlation to the values of the same in the saliva of children from the experimental group $(p<0,001)$; The examined correlation between the total antioxidant capacity of the saliva in children with primary dentition and the presence of dental caries, showed that there is a negative medium strong significant correlation ( $p<0,05$; the levels of $\operatorname{IgA}$ and $\operatorname{Ig} G$ in the saliva in children from the control group with primary dentition is significantly greater in correlation to the values of $\operatorname{IgA}$ and $\operatorname{Ig} G$ in the saliva in children from the experimental group $(p<0,001)$; the correlation between the values of the immunoglobulin $A$ and $G$ in the saliva of children with primary dentition and the presence of dental caries, showed that there is a negative medium strong significant correlation $(p<0,05)$.
\end{abstract}

Key words: dmft, saliva, total proteins, antioxidant capacity, IgA and $\operatorname{Ig} G$.

\section{Introduction}

Despite the scientific and technological evolution, dental caries is still one of the leading health concerns throughout the world that affects population groups from all ages, especially school children. There are numerous etiological factors for dental caries, from which most are confirmed etiological factors, but still many remain to be researched to their full extend.

The saliva has different defense mechanisms, such as immunological and enzyme systems, defense mechanisms against bacteria, viruses, fungi,protection of the mucosa and it also promotes its healing properties. One of the most important defense mechanisms is the antioxidant system. [1]

Taking into consideration that the oral cavity is a door into the organism for bacteria from the external environment, the saliva with its antimicrobial proteins is the first line of defense of the host. With the mentioned mechanism the oral mucosa is protected from the colonization of bacteria, while preventing a misbalance of the normal oral flora. The antimicrobial defense of the saliva can be specific and nonspecific. The specific antimicrobial defense is carried out by the immunoglobulin's while the nonspecific antimicrobial defense is represented by numerous antimicrobial peptides i.e. proteins.[2]

The most significant organic components of the saliva are the proteins and the glycoproteins from which the most numerous are prealbumins, albumins, alfa 1 acid glycoprotein, beta lipoprotein, lactoferrin, transferrin, immunoglobulin IgA, IgG, IgM, amylase exc. [2] 
Mahjoub [81] investigated the total antioxidant capacity of the saliva in correlation to dental caries in early childhood. The results showed that the TAC of the saliva is increased in children with dental caries. Tulunglu proved that the total quantity of proteins and the total levels of antioxidants in the saliva increased with the activity of dental caries in children. [3]

The correlation between dental caries and antioxidants is not a common topic in the available literature. It is a recent claim that the misbalance in the levels of free radicals, reactive oxygen types and antioxidants in the saliva can play a significant role in the onset and evolution of dental caries. [4]

Tulunoglu and col. [3] examined the total antioxidant capacity of the saliva and the serum in children with and without dental caries and came to the conclusion that the same is significantly increased in both mediums $(\mathrm{p}<0,001)$ in examinees with an increased DMFT. The total antioxidant capacity of the saliva had a positive correlation with dental caries and with the increase of the DMFT values the level of the antioxidant capacity increased.

The antimicrobial and antiviral effects of the saliva are a product of the action of the immunoglobulins from the class $\operatorname{IgA}$, IgG and less frequently from IgM. Having in mind that the saliva is in constant contact with all of the tissues in the oral cavity and that it contains protective components, the upkeep of the health of the oral mucosa and the other tissues, means that these elements must be constantly present in physiological conditions. The salivary immunoglobulins are a necessity in the conservation of the oral tissues and organs, because they have an antimicrobial effect. [5]

The immunoglobulins in the saliva are synthesized locally in the plasma cells of the enamel intersticium. The existence of multiple types of immunoglobulins is confirmed in the saliva, from which the most important are: IgA, IgG and IgM. The immunoglobulin IgA is the mostnumerous and is in a unique form ( a dimmer combination of $\operatorname{IgA}$ and secretive components) which in the literature is known as secretory immunoglobulin A (sIgA). Together, IgG and sIgM form a secretory immunoglobulin system, that is significant for the specific, humoral defense of the mucosa of the oral, digestive and respiratory system, and that secretory immunoglobulin system is responsible for the defense of the host from the penetration of antigens and microbiological infective agents. [5]

The most significant organic components of the saliva are the proteins and the glycoproteins from which the most numerous are prealbumins, albumins, alfa 1 acid glycoprotein, beta lipoprotein, lactoferrin, transferrin, immunoglobulin $\operatorname{IgA}, \operatorname{IgG}$, IgM, amylase exc.[6]

Motivated from new challenges and findings, our study represents an attempt to recognize the complexity of the etiology of dental caries whilst assessing the level of total proteins in the saliva, the level of the immunoglobulin IgA and IgG in the saliva and the total antioxidant capacity of the saliva in children and their correlation with the intensity of dental caries.

\section{Examinees included in the study}

\section{Materials and methods}

For the realization of our goals weincluded 74 preschool children (35 female and 39 male), picked randomly, at the age from 4-6 years, from the elementary schools in Shtipwhich were divided into two groups:

I. Control group - 31 examinee without dental caries, dental fillings and extraction $(\mathrm{dmft}=0)$

II. Experimental group - 43 examinees with dental caries, dental fillings and extracted teeth

\section{Clinical examinations}

The clinical examinations were focused toward verification of data about the prevalence and intensity of dental caries. In our study we used the Klein-Palmer index which represents the presence of absence of dental caries, and the dmft and dmfs index that represents the presence or absence of dental caries in primary teeth.

The clearly visible lesion on the surface of the tooth is registered as dental caries, while the change in the transparency and the beginning of demineralization with an intact surface and without cavitation is noted as a healthy tooth. The intensity of dental caries was noted and interpreted in the following way [7]:

a) $\leq 3$ - low dental caries risk

b) 4-6- medium dental caries risk

c) $\geq 7$-high dental caries risk

\section{Laboratory examinations}

Saliva samples were taken in the morning a minimum of 1 hour after the last meal and after washing teeth.

The assessment of the proteins in the saliva was done with the factory testNovex proteine fromNovexBiotech, Salt Lake City, UT 84116, USA.The principle behind the Biuret method is a photometric colorimetric test, which test is carried out by combining pyrogallol and molybdenum in an acid environment, from which a pyrogallol red-molybdenum complex is formed, which connects to the base amino groups of the 
protein molecules in the saliva sample, wherefrom a blue-purple complex is formed, which maximally absorbs light at $546 \mathrm{~nm}$. The intensity of color is proportional to the concentration of proteins in the saliva sample.

The assessment of the total antioxidant capacity of the saliva was done with the assessment of the antioxidant capacity of the saliva which is a product of thesubstance2,2'-azino-bis(3-ethylbenzothiazoline-6sulphonic acid)(ABTS), which we incubated with peroxidase and hydrogen peroxide from which a cation radical was formed, $\mathrm{ABTS}^{+}$, with a relatively stable blue-green color, whose intensity is measured at $600 \mathrm{~nm}$. The antioxidants present in the saliva sample suppress the level of production of this color which is proportional to the concentration of antioxidants in the sample.

For the assessment of the antioxidant capacity of the saliva we used the factory test - Total Antioxidant Capacity (PAO) Assay, Biomedica Company, USA.

The assessment of $\operatorname{IgG}$ and $\operatorname{IgA}$ in the saliva was done with factory ready tests Synergy ${ }^{\mathrm{TM}}$ Microplate Readers and HTRF® Detection fromBioTek Instruments, Inc., headquartered in Winooski, VT, USA. The principle of the imunoturbidimetric methodology for the assessment of the $\operatorname{IgA}$ and $\operatorname{IgG}$ is based on the fact that proteins in the saliva form immune complexes in an immunohistochemical reaction with specific common anti IgG and IgA antibodies. These complexes blur the samples on a maximal light of $334 \mathrm{~nm}-340 \mathrm{~nm}$. The intensity of the blurring is proportional to the concentration of the immunoglobulins in the sample. The results are analyzed through a standardized graph.

\section{Statistical analysis of the data}

The analysis of the data was carried out in the statistical program Statistica 7.1 for Windows and SPSS Statistics 17.0. The following methods were used:

- Descriptive Statistics (Mean; Std.Deviation; $\pm 95,00 \%$ CI; Minimum; Maximum);

- $\quad$ The differences were tested with the $t$-test for the independent samples $(t)$ and the Mann - Whitney $U$ test $(\mathrm{Z} / \mathrm{p})$

- For the examination of the correlaion between the presence of dental caries as a variable and proteins, and for the total antioxidant capacity and $\operatorname{IgA}$, IgG as an independent occurrence we used Multiple Regression (R);

The significance is set at $\mathrm{p}<0,05$. The data are presented in tables and graphs.

\section{Results}

The results for the examined parameters are presented in the following tables and graphs.

The descriptive statistics of the values which take into consideration the components of the dmft(dental caries, extraction, dental fillings) in children with primary dentition in the experimental group are presented in table 1 and graph 1.

The values of the dental caries vary in the interval $2,88 \pm 1,69 ; \pm 95,00 \% \mathrm{KI}: 2,36-3,40$; the minimal value is 0 and the maximum is 8 . The values for the extraction vary in the interval $0,51 \pm 0,83 ; \pm 95,00 \% \mathrm{KI}: 0,26-0,77$; the minimal value is 0 and the maximum value is 3 . The values for the dental fillings vary in the interval $1,21 \pm 1,61$; $\pm 95,00 \% \mathrm{KI}:-0,71-1,71$; the minimal value is 0 and the maximal value is 6 .

Table 1. Dental caries\& Extraction \& Dental Fillings / Descriptive statistics

\begin{tabular}{|c|c|c|c|c|c|c|c|}
\hline Parameters & Valid N & Mean & $\begin{array}{c}\text { Confidence } \\
\mathbf{- 9 5 , 0 0 \%}\end{array}$ & $\begin{array}{c}\text { Confidence } \\
\mathbf{9 5 , 0 0}\end{array}$ & Minimum & Maximum & Std.Dev. \\
\hline Dental caries & 43 & 2,88 & 2,36 & 3,40 & 0 & 8 & 1,69 \\
\hline Extraction & 43 & 0,51 & 0,26 & 0,77 & 0 & 3 & 0,83 \\
\hline Dental filling & 43 & 1,21 & 0,71 & 1,71 & 0 & 6 & 1,61 \\
\hline
\end{tabular}




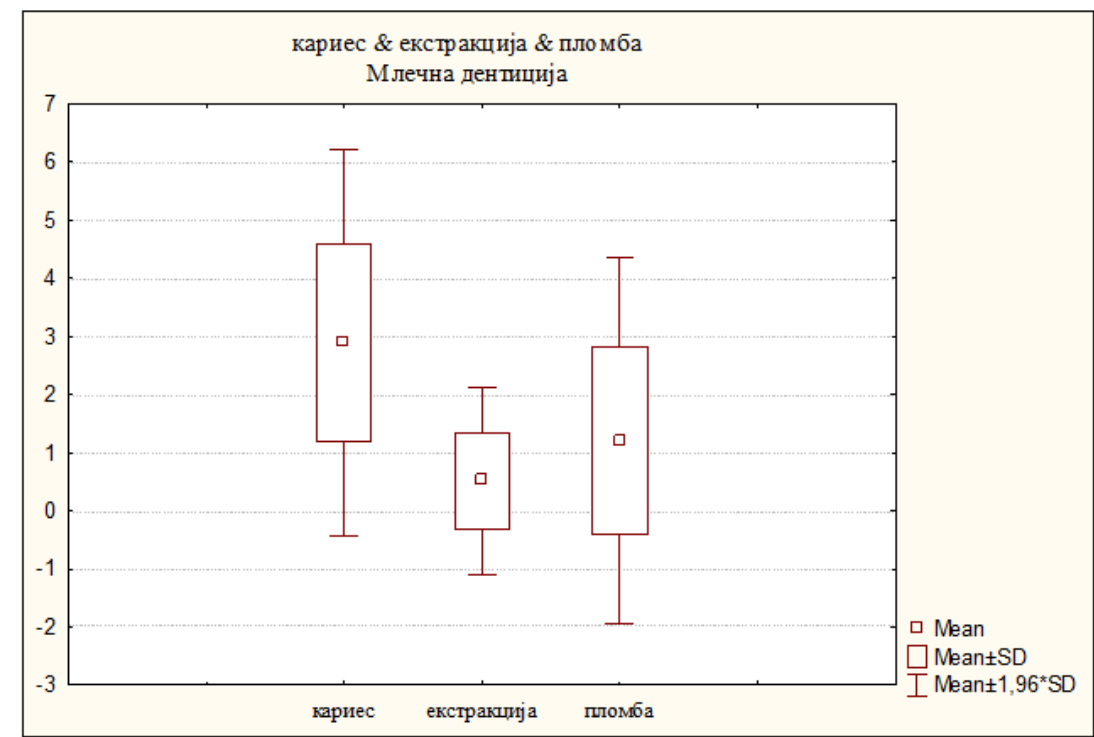

Graph 1. Dental caries \& Extraction \& Dental filling / Descriptive statistics

The descriptive statistics of the values which take into consideration dental caries and dental fillings / by surface / in children with primary dentition in the experimental group (table 2 and graph 2) show that the values vary in the interval 4,63 $\pm 2,79 ; \pm 95,00 \% \mathrm{KI}: 3,77-5,49$; the minimal value is 0 and the maximum value is 12. The values for dental fillings by surfaces vary in the interval $1,63 \pm 2,36 ; \pm 95,00 \% \mathrm{KI}: 0,90-2,35$; the minimal value is 0 and the maximum value is 9 .

Table 2 Dental caries \& dental fillings - by surface / Descriptive statistics

\begin{tabular}{|c|c|c|c|c|c|c|c|}
\hline Parameters/surfaces & Valid N & Mean & $\begin{array}{c}\text { Confidence } \\
-95,00 \%\end{array}$ & $\begin{array}{c}\text { Confidence } \\
+95,00\end{array}$ & Minimum & Maximum & Std.Dev. \\
\hline Dental caries & 43 & 4,63 & 3,77 & 5,49 & 0 & 12 & 2,79 \\
\hline Dental fillings & 43 & 1,63 & 0,90 & 2,35 & 0 & 9 & 2,36 \\
\hline
\end{tabular}

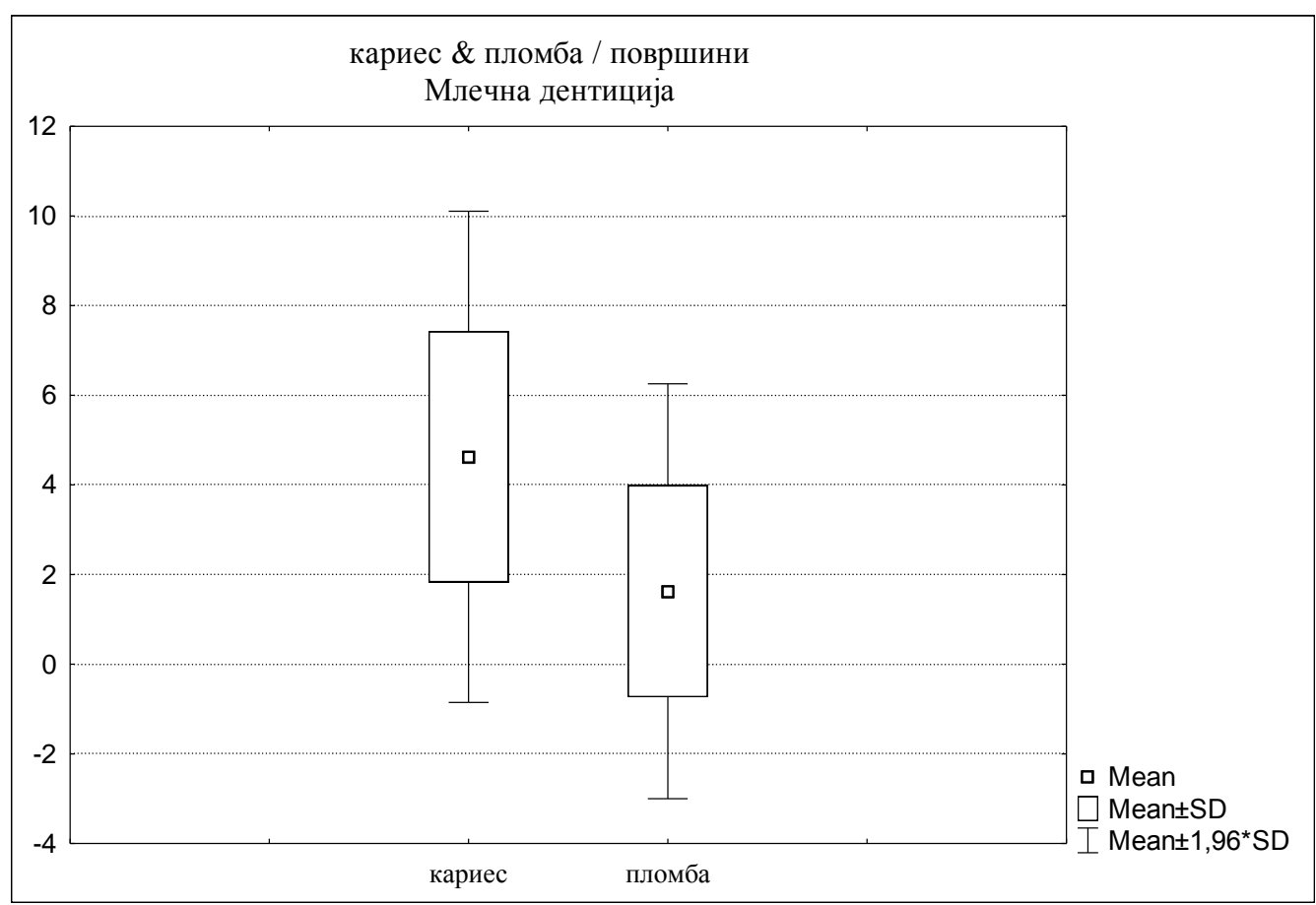

Graph 2. Dental caries \& fillings - surface / Descriptive statistics

The intensity of dental caries in children with primary dentition are presented on table 3 .In the experimental group from a total of $43(58,10 \%)$ children, $15(20,30 \%)$ had a low dental caries risk $(<=3), 20$ $(27,99 \%)$ had a medium dental caries risk (4-6) and $8(10,80 \%)$ had a high dental caries risk $(=>7)$. In the control group all $31(41,90 \%)$ children were with a low dental caries risk $(<=3)$. 
Correlation of dental caries, total proteins, total antioxidant capacity, immunoglobulin A and $G \ldots$.

In the presented distribution of data which take into consideration the intensity of dental caries in children with mixed dentition, the Fisher's Exact Test $=36,52$ and $p<0,001(p=0,000 / 0,000-0,000)$ and there is a significant difference between the two groups (table 3 ).

Table 3. Group / dmft index - intensity

\begin{tabular}{|c|c|c|c|c|c|c|}
\hline & & & \multicolumn{3}{|c|}{$\square \square \square \square \square \square \square \square$} & \multirow[t]{2}{*}{ Total } \\
\hline & & & $\begin{array}{c}\text { Low dental caries } \\
\text { risk }\end{array}$ & $\begin{array}{l}\text { Medium dental } \\
\text { caries risk }\end{array}$ & $\begin{array}{l}\text { High dental caries } \\
\text { risk }\end{array}$ & \\
\hline \multirow[t]{4}{*}{ Group } & \multirow[t]{2}{*}{ Experimental } & Count & 15 & 20 & 8 & 43 \\
\hline & & $\%$ of Total & $20,3 \%$ & $27,0 \%$ & $10,8 \%$ & $58,1 \%$ \\
\hline & \multirow[t]{2}{*}{ Control } & Count & 31 & 0 & 0 & 31 \\
\hline & & $\%$ of Total & $41,9 \%$ &, $0 \%$ &, $0 \%$ & $41,9 \%$ \\
\hline
\end{tabular}

The descriptive statistics of the values of total proteins, the total antioxidant capacity and $\operatorname{IgG}$ and $\operatorname{Ig} \mathrm{A}$ in the saliva in children from the control group is presented on table 4 . The total proteins vary in the interval $5,89 \pm 2,53 \mathrm{gr} / 1 ; \pm 95,00 \% \mathrm{KI}: 4,96-6,82$; the minimal value is $1,30 \mathrm{gr} / 1$ and the maximal value is $9,80 \mathrm{gr} / 1$; The values of the total antioxidants vary in the interval $46,16 \pm 29,29 \mathrm{mmol} / 1 ; \pm 95,00 \% \mathrm{KI}: 35,41-56,90$; the minimal value is $8,30 \mathrm{mmol} / \mathrm{l}$ and the maximum value is $122,10 \mathrm{mmol} / \mathrm{l}$. The values of IgA in children from the experimental group vary in the interval $139,07 \pm 25,20 \mathrm{mgr} / \mathrm{ml} ; \pm 95,00 \% \mathrm{KI}: 129,82-148,31$; the minimal value is $16,10 \mathrm{mgr} / \mathrm{ml}$ and the maximal value is $155,50 \mathrm{mgr} / \mathrm{ml}$; The values of IgG vary in the interval $14,51 \pm 1,37$ $\mathrm{mgr} / \mathrm{ml} ; \pm 95,00 \% \mathrm{KI}: 14,00-15,01$; the minimal value is $11,90 \mathrm{mgr} / \mathrm{ml}$ and the maximal value is $18,20 \mathrm{mgr} / \mathrm{ml}$;

Table 4. Descriptive statistics - control group

\begin{tabular}{|ccccccccc|}
\hline & Valid N & Mean & $\begin{array}{c}\text { Confidence } \\
-95,00 \%\end{array}$ & $\begin{array}{c}\text { Confidence } \\
+95,00\end{array}$ & Min. & Max. & Std.Dev. \\
\hline Parameters & 31 & 5,89 & 4,96 & 6,82 & 1,30 & 9,80 & 2,53 \\
\hline Total proteins (gr/ml) & 31 & 46,16 & 35,41 & 56,90 & 8,30 & 122,10 & 29,29 \\
\hline IgA $(\mathrm{mgr} / \mathrm{ml})$ & 31 & 139,07 & 129,82 & 148,31 & 16,10 & 155,50 & 25,20 \\
\hline IgG $(\mathrm{mgr} / \mathrm{ml})$ & 31 & 14,51 & 14,00 & 15,01 & 11,90 & 18,20 & 1,37 \\
\hline
\end{tabular}

The total proteins from the experimental group vary in the interval $, 87 \pm 3,67 \mathrm{gr} / 1 ; \pm 95,00 \% \mathrm{KI}: 2,74$ 4,99; the minimal value is $0,00 \mathrm{gr} / \mathrm{l}$ and the maximal value is $15,60 \mathrm{gr} / \mathrm{l}$; The values of the total antioxidants vary in the interval $18,76 \pm 11,93 \mathrm{mmol} / \mathrm{L} ; \pm 95,00 \% \mathrm{KI}: 15,09-22,43$; the minimal value is $5,10 \mathrm{mmol} / \mathrm{L}$ and the maximal value is $55,20 \mathrm{mmol} / \mathrm{l}$. The values of $\mathrm{IgA}$ in examinees from the experimental group vary in the interval $120,37 \pm 11,37 \mathrm{mgr} / \mathrm{ml} ; \pm 95,00 \% \mathrm{KI}: 116,87-123,87$; the minimal value is $100,90 \mathrm{mgr} / \mathrm{ml}$ and the maximal value is $154,00 \mathrm{mgr} / \mathrm{ml}$. The values of $\mathrm{IgG}$ vary in the interval $11,82 \pm 1,34 \mathrm{mgr} / \mathrm{ml}$; $\pm 95,00 \% \mathrm{KI}: 11,41-12,24$; the minimal value is $9,80 \mathrm{mgr} / \mathrm{ml}$ and the maximal value is $15,20 \mathrm{mgr} / \mathrm{ml}$ (table 5).

Table 5. Descriptive statistics - experimental group

\begin{tabular}{|ccccccccc|}
\hline Parameters & Valid N & Mean & $\begin{array}{c}\text { Confidence } \\
\mathbf{- 9 5 , 0 0 \%}\end{array}$ & $\begin{array}{c}\text { Confidence } \\
\mathbf{+ 9 5 , 0 0}\end{array}$ & Minimum & Maximum & Std.Dev. \\
\hline Total proteins (gr/l) & 43 & 3,87 & 2,74 & 4,99 & 0,00 & 15,60 & 3,67 \\
\hline Total antioxidants (mmol/l) & 43 & 18,76 & 15,09 & 22,43 & 5,10 & 55,20 & 11,93 \\
\hline IgA(mgr/l) & 43 & 120,37 & 116,87 & 123,87 & 100,90 & 154,00 & 11,37 \\
\hline IgG(mgr/ml) & 43 & 11,82 & 11,41 & 12,24 & 9,80 & 15,20 & 1,34 \\
\hline
\end{tabular}

The difference in the values of total proteins, total antioxidants, $\operatorname{Ig} \mathrm{A}, \operatorname{Ig} \mathrm{A}, \mathrm{OHI}$ in the saliva of children, between the control and experimental group are presented in table 6 . The value of total proteins in the saliva of children from the control group for $\mathrm{Z}=2,88$ and $\mathrm{p}<0,01(\mathrm{p}=0,00)$ significantly is greater in correlation to the value of total proteins in the saliva of children from the experimental group. The value of the total antioxidant capacity of the saliva in children from the control group for $\mathrm{Z}=4,50$ and $\mathrm{p}<0,001(\mathrm{p}=0,00)$ is significantly greater in correlation to the value of the total antioxidant capacity of the saliva in children from the experimental group. The value of $\operatorname{Ig} \mathrm{A}$ in the saliva in children from the control group for $\mathrm{Z}=5,21$ and $\mathrm{p}<0,001(\mathrm{p}=0,000)$ is significantly greater in correlation to the value of $\operatorname{IgA}$ in the saliva of children from the experimental group. The value of IgG in the saliva of children from the control group for $Z=6,17$ and $p<0,001(p 0,000)$ is significantly greater in correlation to the value of $\operatorname{IgG}$ in the saliva of children from the experimental group. 
Correlation of dental caries, total proteins, total antioxidant capacity, immunoglobulin A and $G \ldots$.

Table 7. Difference / Control group \& Experimental group

\begin{tabular}{|c|c|c|c|c|c|c|c|}
\hline Parameter & $\begin{array}{c}\text { Rank Sum } \\
\square \square \square \square \square \square\end{array}$ & $\begin{array}{c}\text { Rank Sum } \\
\square \square \square \square\end{array}$ & $\mathbf{U}$ & $\mathbf{Z}$ & p-level & $\begin{array}{c}\text { Valid N } \\
\square \square \square \square \quad \square\end{array}$ & $\begin{array}{c}\text { Valid N } \\
\square \square \square \square \square \square \square \square \square\end{array}$ \\
\hline TAC (mmol/l) & 1573,50 & 1201,50 & 255,50 & 4,50 & 0,000 & 31 & 43 \\
\hline IgA (mgr/ml) & 1638,50 & 1136,50 & 190,50 & 5,21 & 0,000 & 31 & 43 \\
\hline IgG(mgr/ml) & 1726,00 & 1049,00 & 103,00 & 6,17 & 0,000 & 31 & 43 \\
\hline
\end{tabular}

.1.1 dmft index / Total proteins

Graph 3 presents the examined correlation between the total proteins in the saliva of children with primary dentition and presence of dental caries. For $\mathrm{R}=-0,28(\mathrm{p}<0,05)$ there is a negative medium strong significant correlation. Namely, the increase of the total proteins in the saliva in children is followed with a decrease of dental caries in children.

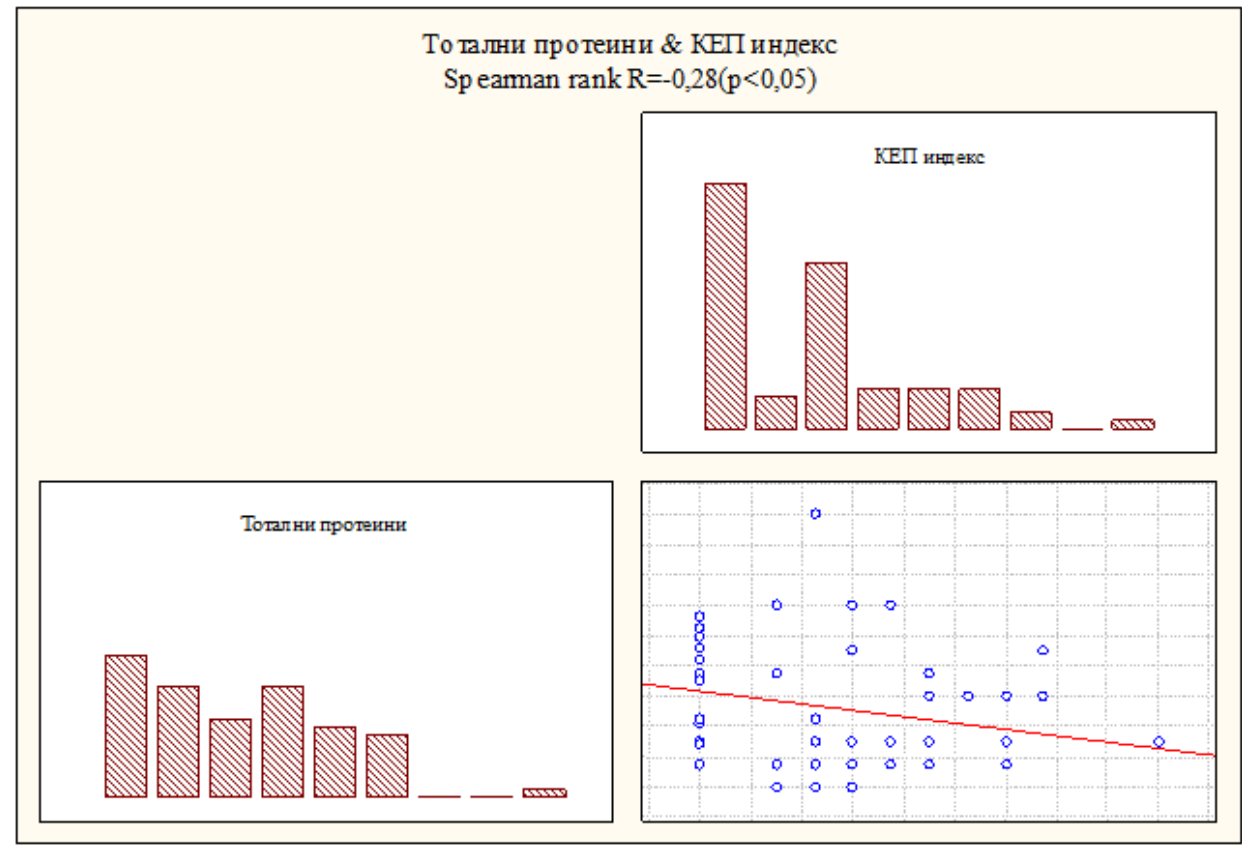

Graph $3 \mathrm{dmft}$ index / total proteins

\section{2. dmft index / Antioxidant capacity}

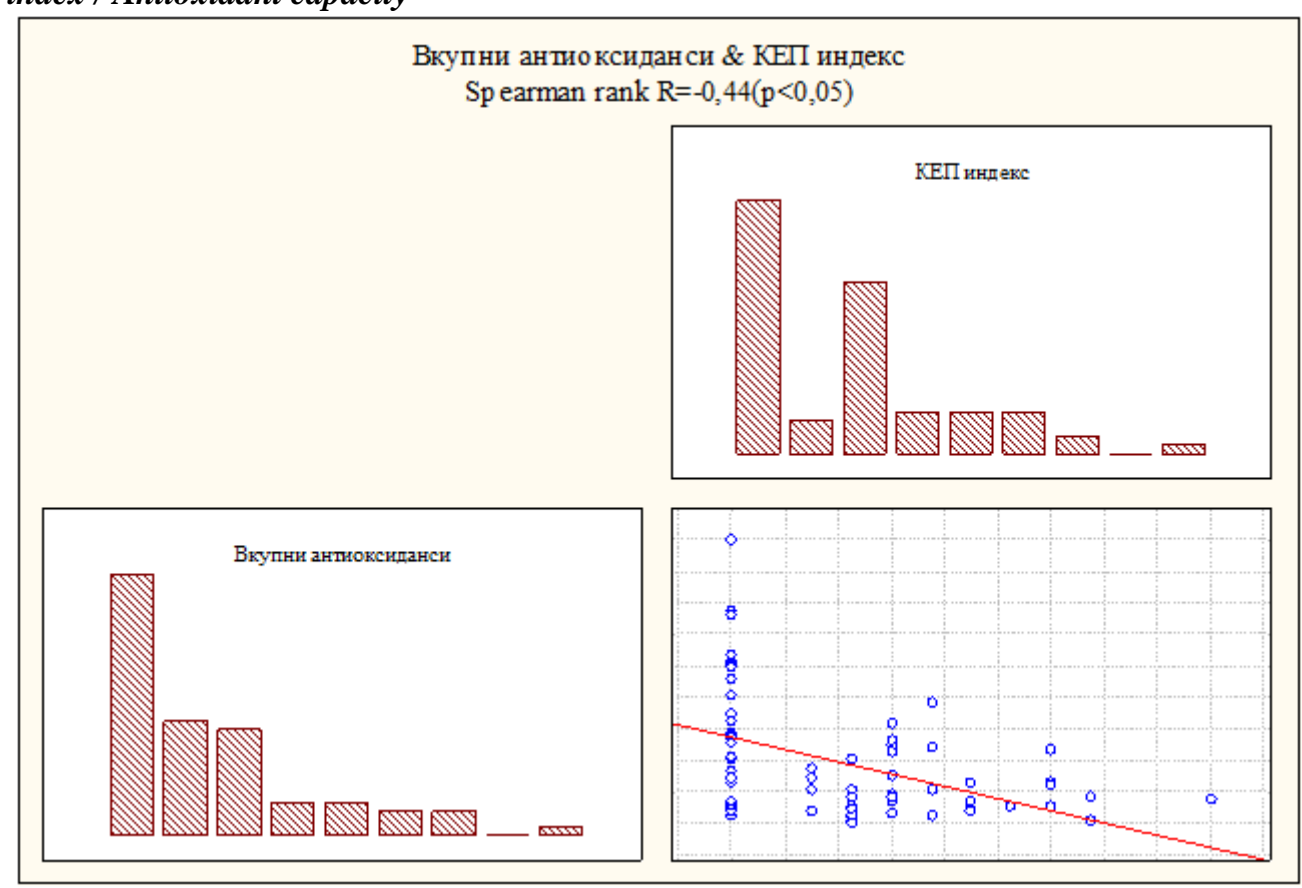

Graph $4 \mathrm{dmft}$ index / antioxidant capacity 
Correlation of dental caries, total proteins, total antioxidant capacity, immunoglobulin A and $G \ldots$.

Graph 4 presents the examined correlation between the total antioxidants in the saliva of children with primary dentition and the presence of dental caries. For $\mathrm{R}=0,44(\mathrm{p}<0,05)$ there is a negative medium strong significant correlation. Namely, the increase in the total antioxidants in the saliva in children is followed with a decrease of dental caries in children.

\section{3. dmft index / IgA}

Graph 5 present the correlation between the values of the immunoglobulin $\mathrm{A}$ in the saliva of children with primary dentition and dental caries. $R=-0,52(\mathrm{p}<0,05)$ there is a negative medium strong significant correlation. The increase in the value of the immunoglobulin A is followed with a decrease in the occurrence of dental caries in children.

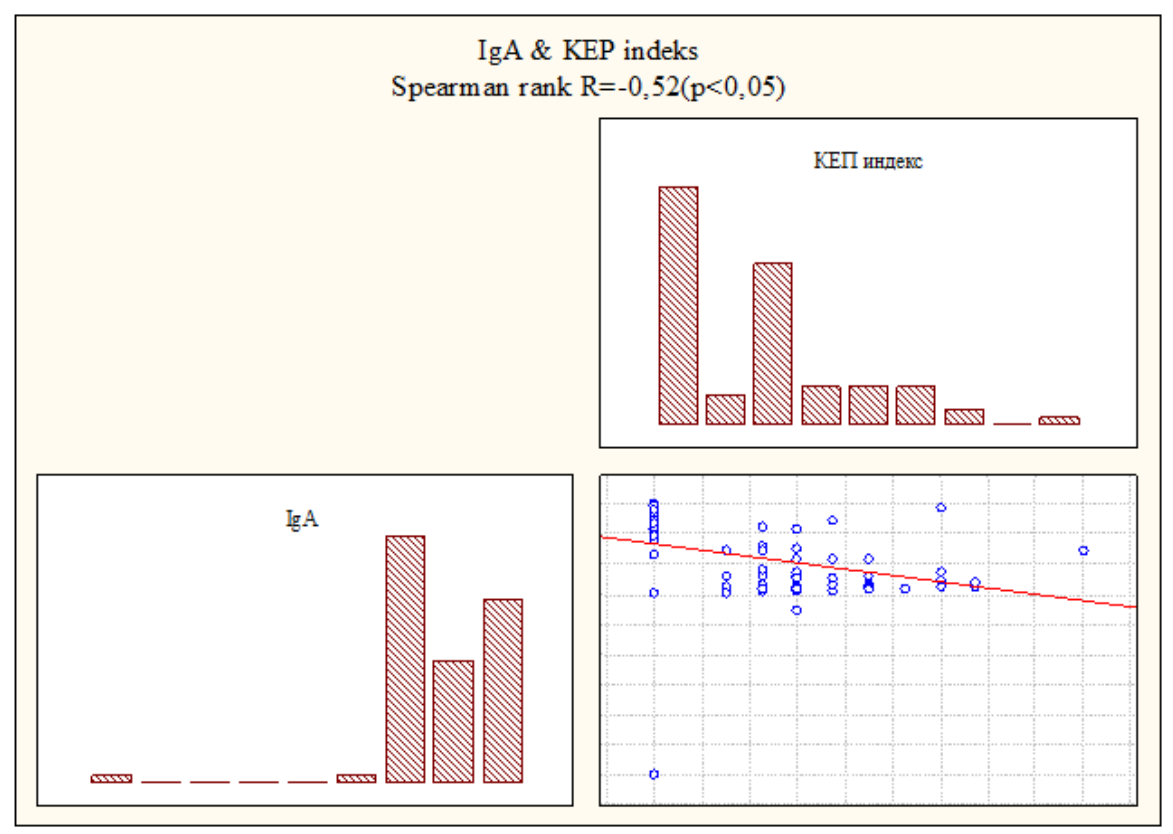

Graph 5. dmft index / IgA

$1.4 \mathrm{dmft}$ index / IgG

Graph 6 presents the examined correlation between the values of the immunoglobulin $\mathrm{G}$ in the saliva in children with primary dentition and the existence of dental caries. $R=-0,64(p<0,05)$ there is a negative medium strong significant correlation. Namely, the increase in the value of the immunoglobulin $\mathrm{G}$ in the saliva in children with a mixed dentition is followed with a decrease in the presence of dental caries in children.

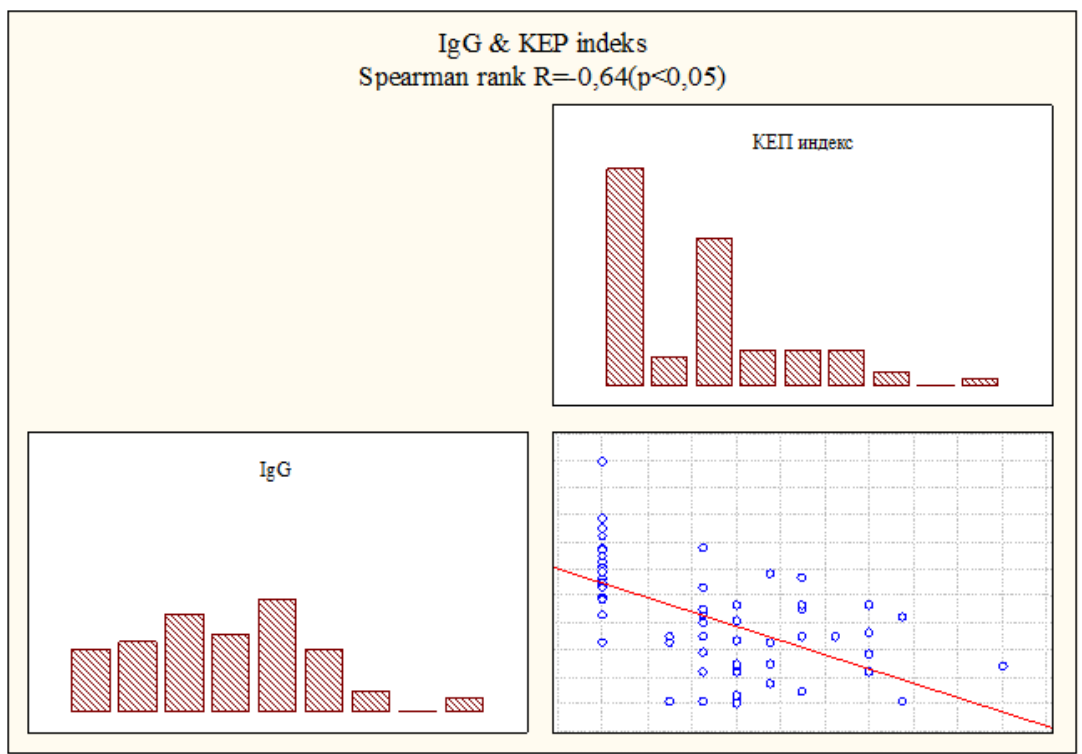

Graph 6. 
Correlation of dental caries, total proteins, total antioxidant capacity, immunoglobulin A and $G \ldots$.

\section{$1.2 \mathrm{dmft}$ index / Analyzed parameters}

The results in table 8 present the examined correlation between the existence of dental caries in children with primary dentition, as a dependent occurrence and the values of the total proteins, the total antioxidant capacity, immunoglobulin $\mathrm{A}$ and immunoglobulin $\mathrm{G}$ as independent parameters. $\mathrm{R}=0,74$ and $\mathrm{p}<0,001(\mathrm{p}=0,000)$ show that there is a very strong significant correlation.

The greatest influence on the examined correlation hadthe immunoglobulin $\mathrm{G}$ (Beta=-0,33), then the immunoglobulin A (Beta $=-0,27)$, the total antioxidant capacity (Beta $=-0,25)$ and the least influence was seen by the total proteins $(B e t a=-0,15)$. By increasing the value of the immunoglobulin $G$ in the saliva by one the value of the dmft index significantly decreased by $0,51 \quad(B=-0,51) p<0,01(p=0,003)$, when the other analyzed parameters stay unchanged.

By increasing the value of the immunoglobulin A in the saliva of children by one the value of the $\mathrm{dmft}$ index significantly decreased by $0,04(\mathrm{~B}=-0,04) / \mathrm{p}<0,01(\mathrm{p}=0,007)$, when the other analyzedparameters stay unchanged. By increasing o the value of the total antioxidant capacity of the saliva by one the value of the $\mathrm{dmft}$ index significantly decreases by $0,03(B=-0,03) / p<0,01(p=0,009)$, when the other analyzed parameters stay unchanged. By increasing the value of the total proteins in the saliva by 1 the value of the $\mathrm{dmft}$ index decreases insignificantly by $0,13(B=-0,13) / p>0,05(p=0,10)$, when the other analyzed parameters stay the same.

Table 8. dmft index / analyzed parameters

\begin{tabular}{|c|c|c|c|c|c|c|}
\hline \multicolumn{2}{|c|}{ Regression Summary for Dependent Variable: KEP ; R= 0,74 ; F(7,66)=11,63 p<0,000 } \\
\hline & Beta & $\begin{array}{c}\text { Std.Err. } \\
\text { of Beta }\end{array}$ & B & $\begin{array}{c}\text { Std.Err. } \\
\text { of B }\end{array}$ & $\mathrm{t}(66)$ & p-level \\
\hline Intercept & & & 15,09 & 2,07 & 7,28 & 0,000 \\
\hline Total proteins (gr/l) & $-0,15$ & 0,09 & $-0,13$ & 0,08 & $-1,68$ & 0,098 \\
\hline TAC (mmol/l) & $-0,25$ & 0,099 & $-0,03$ & 0,01 & $-2,67$ & 0,009 \\
\hline IgA (mgr/ml) & $-0,27$ & 0,10 & $-0,04$ & 0,01 & $-2,79$ & 0,007 \\
\hline IgG (mgr/ml) & $-0,33$ & 0,11 & $-0,51$ & 0,16 & $-3,11$ & 0,003 \\
\hline
\end{tabular}

\section{Discussion}

According to Bader and col. [96] the global question about the oral health of children is mostly focused on dental caries. Because of its high prevalence in the world, Edelstein [8] defined dental caries in children as a "Pandemic" which mainly is characterized by a high level of non-treated carious lesion which in an advanced phase cause pain and functional limitations. The treated carious lesion have a significant influence on the general health of the children which in turn has an influence on the social and economic wellbeing of the community, says Baelum and also notes that the untreated carious lesion are with a drastically higher prevalence in non-developed countries and countries in development. [9]

The experiments and clinical examinations that are carried out so far show that the onset of dental caries is caused by different risk factors which can act independently or in association. [10,11]

The goals we set, and the examinations we did, were focused toward the assessment of salivary component associated to dental caries, but for an easier interpretation of the results in the discussion we will first discuss the results we got about the dental health in the examinees with primary dentition.

The results we got that presented the values of the total dmft index vary in the interval $4,63 \pm 1,99$, for dental caries they vary in the interval $2,88 \pm 1,69$, for extracted teeth they vary in the interval $0,51 \pm 0,83$ and for teeth with dental fillings they vary in the interval $1,21 \pm 1,61$.

The descriptive statistics of the values of the $\mathrm{dmft}$ by tooth surfaces in children, with primary dentition varies in the interval $6,60 \pm 3$,13in which the minimal value is 2 and the maximum value is 16 . The values of the components of the dmft index according to teeth surfaces, for dental caries, vary in the interval 4,63 $\pm 2,79$, in which the maximum value is 12 carious surfaces opposed to the teeth with dental fillings, according to surfaces, which had less and vary in the interval 1,63 $\pm 2,36$, with a maximum of 9 surfaces.

The data which takes into consideration the intensity of dental caries in children with primary dentition from the experimental group, show that, from a total of $43(58,10 \%)$ children, $15(20,30 \%)$ had a low dental caries risk (<=3), $20(27,00 \%)$ children had a medium dental caries risk (4-6), and $8(10,80 \%)$ children had a low dental caries risk $(=>7)$, while all of the examinees from the control group had a low dental caries risk $(<=3)^{3}$

In the presented distribution of data which takes into consideration the intensity of dental caries in children with primary dentition, we can notice a significant difference between the two examined groups $\mathrm{p}<0,001$.

Dawani [104] carried out a study in preschool children from Karachi where the prevalence of dental caries in primary teeth in 4-5 year old children was $76 \%$, which corresponded to the prevalence in Saudi Arabia $(75 \%)$ and the United Arab Emirates where the prevalence is also high (70-80\%) which are worse results from the ones we got. $[12,13]$ 
The mentioned results which we got for the dmft index in children are still far off from the results published by researchers in developed countries, such as Sweden where $69 \%$ of 3 year old children did not have dental caries or Brisbane, Australia where $66 \%$ of children at the age from 4-6 years did not have dental caries. $[14,15]$

The most probable explanation for these differences can be the inequality of the economical conditions andresources, the efficiency of the policies for fluoridation, the efficiency of the health system, the availability and use of refined sugars, different standards for oral health in children and parents about the diet and oral hygiene, the lifestyle and the motivational status of the parents and children. [16]

There is some data in the literature about the possible correlation between the proteins and dental caries because many proteins such as statherin, the acidic PRP's and cystatins have a major role in the protective and reparative system which is important for the integrity of the teeth. Still, there is very little evidence about the correlation of cystatin and the prevalence of dental caries.

Tabak and col. [17[ show that there is inverse relationship between the level of cystatin and the levels of cystatin in a non-stimulated saliva and the level of active dental caries in the past, while the study carried out by Shomers and col. [18] suggests that there is no association between the concentration of cystatin and dental caries.

The results of our study about the total proteins in the saliva from the experimental group varied in the

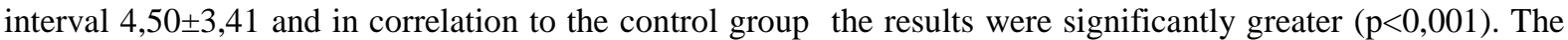
correlation between the total proteins in the saliva of children with primary dentition and the existence of dental caries is with a negative medium strong significant correlation $(\mathrm{p}<0,05)$, the increase in the total proteins in children is followed with a decrease in the presence of dental caries in children.

Guo and col. studied the correlation between the total proteins in the saliva and the dental caries in examinees with a primary dentition and confirmed that the role of the proteins in the dental caries incidence is unclear and differs from the results we got. Still the author points out that the decrease in the total protein and the decrease in the antimicrobial activity can play a role in the incidence of dental caries and gingivitis. [19]

There are a very little number of studies that have studied the correlation between the antioxidant capacity of the saliva and the dental caries, but Tulunoglu [3] confirmed that the total quantity of proteins and the total level of antioxidants in the saliva were increased in the children with active carious lesion.

The values that present the total antioxidants in the saliva of examinees from the control group varied in the interval $46,16 \pm 29,29 \mathrm{mmol} / \mathrm{l}$ and in the examinees from the experimental group that value varied in the interval $18,76 \pm 11,93 \mathrm{mmol} / \mathrm{l}$; in children from the control group that value is for $\mathrm{p}<0,001(\mathrm{p}=0,000)$ greater in correlation to the children from the experimental group.

The correlation between the total antioxidants in the saliva of children with a primary dentition and the presence of dental caries is with a negative medium strong significant correlation $(p<0,05)$ and with the increase of the total antioxidants in the saliva of children the presence of dental caries is decreased.

Our results are in accordance to the results from Panjamurthy [20] who discovered that the total antioxidant capacity is increased in children with dental caries. Even though the activity of the saliva is associated with an increased suspension of proteins and an increased cariogenic activity, McDevitt [21] and Battino [22] point out that the differences in the total antioxidant capacity between the examinees with and without dental caries are not significant, which differs from our results. ${ }^{18}$

The antibacterial and antiviral activity of the saliva is mainly carried out by the immunoglobulin's from the class $\operatorname{Ig} \mathrm{A}, \operatorname{IgG}$ and less frequently IgM. Taking into consideration that the saliva is in constant contact with the tissues from the oral cavity and that it contains component with a defensive role, the upkeep of the health of the oral mucosa and the other oral tissues, means that all of these elements have to be present in physiological circumstances. The salivary immunoglobulins are necessary in the preservation of the oral tissues and organs because they have a very significant antimicrobial effect. [23,24,25]

The values which we got for the levels of $\operatorname{IgA}$ in the saliva of examinees from the control group vary in the interval $139,07 \pm 25,20 \mathrm{mg} / \mathrm{ml}$ and in the examinees from the experimental group they vary in the interval $120,37 \pm 11,37$ which is significantly greater in correlation to the value we got from the saliva samples from the experimental group $(\mathrm{p}<0,001)$.

The values of $\mathrm{IgG}$ in the salivaof examinees from the control group, vary in the interval from $14,51 \pm 1,37 \mathrm{mg} / \mathrm{ml}$, and in the examinees from the experimental group they vary in the interval from $11,82 \pm 1,34$ $\mathrm{mg} / \mathrm{ml}$ and are significantly greater in correlation to the values of $\mathrm{IgG}$ in the saliva of children from the experimental group $(\mathrm{p}<0,001)$.

In the examined correlation between the values of the immunoglobulin $A$ and $G$ in the saliva of children with primary teeth and the presence of dental caries, we can see that there is a negative medium strong significant correlation $(\mathrm{p}<0,05)$, and the increase in the values of the immunoglobulins in the saliva in children is followed with a decrease in the presence of dental caries. ${ }^{20}$ 
Boltan and McGhee [26,27] published that the level of dental caries and the total concentration of the secretory $\operatorname{IgA}$ in the saliva have a negative correlation which is in correspondence to the results which we got, and at the same time Boltan and McGhee claim that the majority of people which are with a high dental caries risk had S.mutans in the saliva. Cogulu opposed that claim and published that the level of the secretory $\operatorname{Ig} \mathrm{A}_{1}$ and $\operatorname{IgA}_{2}$ antibodies of streptococcus mutans are relatively equal in children with and without dental caries which is a product of the change of the true percentage and concentration of the secretory $\operatorname{Ig} \mathrm{A}_{1}$ and $\operatorname{Ig} \mathrm{A}_{2}$ in the saliva in children from birth to adolescence. [26]

The studies carried out by Bagherian and col. [29] carries out with an aim to compare the sIgA and IgG in the saliva of children with KRD earlychildhoodcareiesand without dental caries, show that the average level of concentration in the salivary $\operatorname{sgA}$ and $\operatorname{IgG}$ were significantly greater in children with $\operatorname{KRD}(p<0,05)$ early childhoodcaries. The conclusion was that a high concentration of the secretory immunoglobulins in children with KRD can be linked to an increased antigenic load which leads to an increased production of antibodies.

The hypothesis which we set for the determination of the correlation of the examined parameters with the onset of dental caries in children with a primary dentition, was with a very strong significant correlation $(\mathrm{p}<0,001)$ where the greatest influence was seen by the immunoglobulin $\mathrm{G}$.

From all the mentioned parameters which we studied, we can conclude that the clinical relevant assessment of the individual dental caries activity cannot be based on a single parameter nor can the sensitivity or specificity of the tests be achieved with the needed selectivity. If the number of component taken into consideration is increase the precision of the assessment of the dental caries risk is increased, which is why we decided to include them into our study.

Following the guidelines of the WHO for the preventive programs and their use in populations with different DMFT throughout different countries in the world and transforming them in our country we concluded that there is bad oral health, which suggests a necessity to carry out national strategies for fighting and prevention of dental caries in all age groups of children.

We think that the use of the preventive strategies can quickly and efficiently decrease the dental caries score, especially in the youngest population, with which we can create new generations with good oral health equivalent to the oral health in children in developed countries.

\section{References}

[1]. Błauz A, Pilaszek T, Grzelak A, Dragan A, Bartosz G. Interaction between antioxidants in assays of total antioxidant capacity. Food ChemToxicol. 2008;46:2365-8.

[2]. Nagler RM. Salivary glands and the aging process:mechanistic aspects, health-status and medicinal-efficacy monitoring. Biogerontology. 2004;5:223-33

[3]. Tulunoglu O, Demirtas S, TulunogluI.Total antioxidant levels of saliva in children related to caries, age, and gender. Int $\mathrm{J}$ Paediatr Dent. 2006;16:186-91.

[4]. Battino M, Ferreior MS, Gallardo I, Newman HN, Bullon P. Theantioxidant capacity of saliva. J ClinPeriodontol. 2002;29:189-94

[5]. Bokor-Bratiæ M. Clinical significanceof analysis of immunoglobulin A levels in saliva, Med Pregl.1999,53,(3-4),164-8.

[6]. Nagler RM. Salivary glands and the aging process:mechanistic aspects, health-status and medicinal-efficacy monitoring. Biogerontology. 2004;5:223-33

[7]. Oral Health Surveys:Basic methods. $4^{\text {th }}$ ed.Geneva:WorldHealtchOrganizationHO :1997

[8]. Edelstein B. The dental caries pandemic and disparities problem. BMC Oral Health 2006;15(Suppl 1):S2

[9]. Baelum V, van PalensteinHelderman W, Hugoson A, Yee R, Fejerskov O. Global perspective on changes in the burden of caries and periodontitis: implications for dentistry. J Oral Rehabil 2007;34:872-906.

[10]. National Survey on Oral Health and Nutritional Status in the Philippines. Philippine Department of Education, 2006

[11]. Cariño KM, Shinada K, Kawaguchi Y. Early childhood caries in northern Philippines. Community Dent Oral Epidemiol 2003;31:81-89.

[12]. [105] M. I. Al-Malik, R. D. Holt, and R. Bedi, "Prevalence and patterns of caries, rampant caries, and oral health in two- to fiveyear-old children in Saudi Arabia," Journal of Dentistry for 106.Children, 2003:70(3) : 235-242.

[13]. [106] El-Nadeef H.,Hassab E., Al-Hosani,E National survey of the oral health of 5-year-old children in the United Arab EmiratesEastern Mediterranean Health J2010:16(1) : 51-55

[14]. Hugoson A., Koch G., Helkimo A. N., Lundin S.-A.Caries prevalence and distribution in individuals aged 3-20 years in Jonkoping, Sweden, over a 30-year period (1973-2003)," International Journal of Paediatric Dentistry, 2008;18(1) : 18-26.

[15]. [108] HallettK. B., O'Rourke P. K.Dental caries experience of preschool children from the north Brisbane region.Australian Dental Journal, 2002,47(4):31-338.

[16]. JDawani, N. Nisar, N. Khan, S. Syed, and N. Tanweer, "Prevalence and factors related to dental caries among pre-school children of Saddar town, Karachi, Pakistan: a cross-sectional study,” BMC Oral Health, 2012;12(1):159-164

[17]. Tabak LA, Bowen WH, van Wuyckhuyse B, Frank D, Bessette J, PageDJ, et al (1994). Levels of cystatin in whole saliva of children:association with oral health status (abstract). Caries Res 28:182.

[18]. Shomers JP, Tabak LA, Levine MJ, Mandel ID, Hay DIroperties of cysteine-containing phosphoproteins from humansubmandibular-sublingual saliva. / Dent Res 61:397-399.

[19]. Guo L, Shi W.Salivary biomarkers for caries risk assessment. J Calif Dent Assoc. 2013 Feb;41(2):107-9, 112-8.

[20]. Panjamurthy K, Manoharan S, Ramachandran CR. Lipid peroxidation and antioxidant status in patients with periodontitis. Cell MolBiol Lett. 2005; 10:255-64.

[21]. McDevitt JT. Saliva as the next best diagnostic tool. J Biochem. 2006;45:23-5.

[22]. Battino M, Ferreiro MS, Gallardo I, Newman HN, Bullon P. The antioxidant capacity of saliva. J ClinPeriodontol. 2002;29:18994. 
[23]. Uberos J. ,Alarcón A.,Peñalver M., Ruiz E., González J.,CastejonH. Influence of the antioxidant content of saliva on dental caries in an at-risk community.British Dental Journal 205, E5 (2008) Published online: 13 June 2008 | doi:10.1038/sj.bdj.2008.520

[24]. Tappuni AR, Challacombe SJ (1994). A comparison of salivaryimmunoglobulin A (IgA) and IgA subclass concentrations inpredentate and dentate children and adults. Oral MicrobiolImmunol 9:142-145.

[25]. Biesbrock, A. R., M. S. Reddy,. Interaction of a salivary mucin-secretory immunoglobulin A complex with mucosal pathogens. Infect. Immun.1991, 59,(10), 3492-3497.

[26]. Boltan and HLAVA GL. Initiation of salivary IgA Antibodies to cariogenic microorganisms in children. Correlation with Dental Caries activity. J. Dent Res 1982; vol 61(1):1225-1228.

[27]. McGhee JR, MichalerSM.Immunology of dental caries. Microbial aspects and local immunity. Ann. Rev Microbial 1981; vol 35: $595-638$

[28]. Cogulu D, Sabah E, Kutukculer N, Ozkinay F. Evaluation of the relationship between caries indices and salivary secretory IgA, salivary $\mathrm{pH}$, buffering capacity and flow rate in children Arch Oral Biol 2006;51:23-8.

[29]. Bagherian A, Jafarzadeh A, Rezaeian M, Ahmadi S, RezaityMT.IranComparison of the salivary immunoglobulin concentration levels between children with early childhood caries and caries-free children.JImmunol. 2008 Dec; 5(4):217-21 